\title{
Fugitive aerosols in the intensive care unit: a narrative review
}

\author{
Ciarraí O’'Toole ${ }^{1}$, Mary Joyce ${ }^{2}$, James A. McGrath ${ }^{1}$, Andrew O'Sullivan ${ }^{2}$, Miriam A. Byrne ${ }^{1}$, \\ Ronan MacLoughlin ${ }^{2,3,4 \wedge}$
}

${ }^{1}$ School of Physics \& Ryan Institute's Centre for Climate \& Air Pollution Studies, National University of Ireland Galway, Galway, Ireland; ${ }^{2}$ Aerogen, IDA Business Park, Dangan, Galway, Ireland; ${ }^{3}$ School of Pharmacy and Biomolecular Sciences, Royal College of Surgeons, Dublin, Ireland; ${ }^{4}$ School of Pharmacy and Pharmaceutical Sciences, Trinity College, Dublin, Ireland

Contributions: (I) Conception and design: R MacLoughlin; (II) Administrative support: None; (III) Provision of study materials or patients: None; (IV) Collection and assembly of data: None; (V) Data analysis and interpretation: None; (VI) Manuscript writing: All authors; (VII) Final approval of manuscript: All authors.

Correspondence to: Ronan MacLoughlin. Aerogen, IDA Business Park, Dangan, Galway, H91HE94, Ireland. Email: rmacloughlin@aerogen.com.

\begin{abstract}
The risk of unintended inhalation of fugitive aerosols is becoming a topic of increasing interest in the healthcare arena. These fugitive aerosols may be bioaerosols, generated by the patient themselves through cough or sneeze, or they may be therapeutic medical aerosols, generated by therapeutic medical aerosol generators with the intent of delivery to a specific patient's respiratory tract. This review focus' on therapeutic aerosols in the intensive care unit (ICU) only, those typically generated by nebulisers. In the intensive care environment, patients are generally in receipt of ventilatory support, and the literature suggests that these different support interventions influence fugitive therapeutic medical aerosol emissions in a variety of ways. Predominant ventilatory support interventions include, but are not limited to, invasive mechanical ventilation (MV), non-invasive mechanical ventilation (NIV), high flow nasal therapy (HFNT), and supplemental oxygen delivery in spontaneously breathing patients. Further, factors such as nebuliser type, patient interface, patient breathing pattern, nebuliser position in the patient breathing circuit and medication formulation characteristics also have been shown to exert influence on aerosol concentrations and distance from the source. Here we present the state of the art knowledge in this, as yet, poorly described field of research, and identify the key risks, and subsequently, opportunities to mitigate the risks of unintended exposure of both patients and bystanders during and for periods following the administration of therapeutic aerosols.
\end{abstract}

Keywords: Aerosols; fugitive; vibrating mesh nebuliser (VMN); jet nebulizer (JN); intensive care unit (ICU); secondary inhalation; exposure

Submitted Mar 07, 2020. Accepted for publication Jul 10, 2020.

doi: 10.21037/atm-20-2280

View this article at: http://dx.doi.org/10.21037/atm-20-2280

\section{Introduction}

In the intensive care unit (ICU), unintended inhalation of fugitive therapeutic aerosols is a risk for patients and bystanders alike. Needless to say, the intended target of therapeutic aerosols is the respiratory epithelium for either topical or systemic action in an individual patient, however, aerosol delivery systems, and the equipment to which they are attached, are seldom fully contained or sealed systems that capture the aerosol fraction not deposited in the respiratory tract. This aerosol becomes available for exhalation, or simply bypasses the patient entirely, and is released into the local environment.

\footnotetext{
$\wedge$ ORCID: 0000-0002-3164-1607.
} 
The number and type of therapeutics typically aerosolised is very much dependent on institutional protocols and the individual patient's requirement, but will range from normal physiologic saline to bronchodilators, steroids, antiallergics, mucokinetic agents, antibiotics, antivirals, biologics, immune modulators, and others. Most common in the ICU however are the likes of bronchodilators, which are a first line therapy for acute asthma exacerbations, or antibiotics in the treatment of respiratory tract infections.

The implications for bystander inhalation of these therapeutics are dependent on the mass of therapeutic inhaled, and it's subsequent pharmacokinetics (1). Surprisingly, few studies have comprehensively characterised the risk to bystanders $(2,3)$. In the published literature, it is proposed that unintended inhalation of bronchodilators has been associated with the development of occupational and irritant asthma (3-5). Research shows that respiratory therapists have increased risk of developing asthma after entering the profession, and this could be explained by their exposure to a wide range of aerosolised substances in the hospital workplace $(6,7)$. A recent study derived occupational exposure limits for Albuterol ( $2 \mu \mathrm{g} /$ day), Ipratropium (30 $\mu \mathrm{g} /$ day) and budesonide (11 $\mu \mathrm{g} /$ day) (1). These may be considered very low exposure thresholds, when the standard aerosol treatment prescribed to a patient for each is up to; $10 \mathrm{mg}$ per day Albuterol, $1 \mathrm{mg}$ per day Ipratropium and $2 \mathrm{mg}$ per day Budesonide.

Aerosol-mediated delivery of vaccines is becoming more common, and in this scenario, the risk of unintended immune responses in bystanders may have significant implications. Only a single study was identified that evaluated this, but it found no unintended immune response in vaccine administrators or contacts of the vaccinees (8).

Chronic, low dose exposure over days, months and years of work may, in the case of antibiotics as an example, reduce therapeutic options should those bystanders become ill themselves. It has also been suggested that it could alter the lung microbiota in those exposed (9). Approximately 480,000 people develop multi-drug resistant tuberculosis each year, and exposure to low doses of aerosolised antibiotics could potentially contribute to this among bystanders who come in frequent contact (10). Other antiinfectives such as Ribavirin and Pentamidine have been also studied, and report a range of results from undetectable/ barely detectable body burdens to potential respiratory tract irritant $(11,12)$. Of important note, such exposure is not always through inhalation of the fugitive antiinfective droplet itself. Suspended aerosol droplets will ultimately deposit on local surfaces that may be contacted by bystanders. The risks and adverse side effects associated with dermal exposure following contact with surfaces contaminated with anti-infectives have been described, and include hypersensitivity, allergic skin reactions and respiratory symptoms, making dermal exposure worthy of consideration (13).

Therapeutic aerosols can be generated using any of; pressurised metered dose inhalers, dry powder inhalers, soft mist inhalers or nebulisers. In the treatment of critically ill patients in the ICU however, it is nebulisers that are the most commonly used (14). Within that grouping there are two main classifications; compressor driven jet nebulisers (JN) and vibrating mesh nebulisers (VMN). Briefly, JN require a driving gas flow of between 5 and 13 litres per minute (device dependent) in order to generate stable aerosol, by utilizing the venturi effect (15). Aerosols generated in this fashion are carried by that gas flow to the patient. VMN are electromechanical assemblies that employ the use of a precision manufactured mesh which can vibrate up to 128,000 times per second when electrically powered, and generate aerosol droplets as the liquid drug is pumped through the apertures (16). Aerosols generated in this fashion do not have a carrier air flow, and rely entirely on the movement of air supplied by either the ventilatory support equipment, e.g., mechanical ventilation (MV), or the patient's own inhalation manoeuver.

The duration of treatment time, during which therapeutics are being nebulised, ranges from minutes to hours (17-20), depending on considerations such as the half life of the therapeutic or the nebuliser design, e.g., large volume JN. Consequently, exposure times are affected, with longer therapy times, potentially increasing the risk of bystander exposure.

Current guidance on minimizing exposure is limited, with some nebuliser types providing instruction to use outdoors when aerosolising potentially toxic therapeutics, or provide tubing accessories that can be placed out through an open window (11) in an effort to manage emissions (21). This, however, is not acceptable, controllable or easily practical in the ICU or most other clinical environments. Other approaches described make use of high-efficiency particulate air (HEPA) filter air cleaning systems (22), or hoods placed over the patient in receipt of therapy $(23,24)$.

A review of the current literature indicates that this is not a well described field of research, and many gaps still exist in our knowledge. However, those studies that have been published to date clearly indicate that the unintended 
distribution of therapeutic aerosols within the local environment is heavily influenced by a number of factors including the patient intervention (mode of ventilatory support), patient interface [e.g., face mask, nasal cannula, ventilation hood, mouthpiece (MP) etc.], patient type (adult/ paediatric, breathing pattern) and aerosol generator type.

Here we discuss those identified contributing factors in the context of the published literature, and provide insight into the main effects that influence fugitive aerosols in the ICU setting. For ease of reading, we have segmented this review under the headings of the potential patient intervention.

The review methodology made use of computerised searches of online databases in order to identify key publications. Databases included, but are not limited to; Scopus (Elsevier), ScienceDirect V.4, Web of Science (Thomson Reuters), JSTOR, Academic Search Premier, Wiley Interscience Journals, Wiley Online Library, BioMed Central (Springer), PubMed and Cochrane Library. Searches were also undertaken using Google Scholar. Online searches used relevant terms associated with elements of occupational exposure, with combinations of the following terms: aerosol, nebuliser, jet-nebuliser, occupational exposure, second-hand inhalation, inhalation exposure, aerosol contamination. Citations in relevant publications were checked (backward citation searches) and papers citing relevant publications were studied (forward citation searches).

We present the following article in accordance with the Narrative Review reporting checklist (available at http:// dx.doi.org/10.21037/atm-20-2280).

\section{Review findings}

\section{Spontaneous breathing patients}

Spontaneously breathing patients requiring therapeutic aerosols may or may not require some form of ventilatory support. Those not requiring support, will likely require a handheld nebuliser only. Those patients requiring higher levels of supplemental oxygen and pressure support will make use of a mechanical ventilator, or another source of gas flow and pressure, with the nebuliser included in the breathing circuit.

\section{Nebuliser only}

There are several nebuliser types, however as mentioned, in the ICU they are typically either JN or VMN. Regardless of type, nebulisers will interface with the patient using either a mouthpiece (MP) or facemask (FM). In one study simulating spontaneous breathing in adults, fugitive aerosols were characterised for both JN and VMN used in combination with MP and FM, two commonly used patient interfaces (25). Over a 30-minute period, and at two distances from the simulated patient $(0.8$ and $2.2 \mathrm{~m}$ representing arm's length distance of caregiver administering the dose, and a bystander in an adjacent bed, or nearby, respectively) the highest fugitive aerosol concentrations were recorded for the JN + FM combination. The lowest recorded fugitive aerosol concentration was seen for a VMN + filtered MP arrangement. Across all measurements taken, the JN produced greater fugitive aerosol than the VMN. This was considered to be as a result of the combination of driving JN gas flow rate (set at 8 litres per minute in this study), in combination with the open design of the FMs required for use with JN, where aerosol is driven out through the FM during both inhalation and exhalation phases of the breath. VMN FMs are valved, and so reduce aerosol losses. Whilst not assessed in that study, FM fit against the face was noted to be important, in order to create a seal that prevents further aerosol losses.

\section{Control of aerosol generation/breath actuation}

Some nebulisers claim to have considered emissions in their designs. Breath actuation, that is to say, aerosol generation only during the inhalation phase of the breath, is a logical approach to increasing the delivered dose to the lung, but also concurrently reducing emissions, however, there are few studies confirming that this is actually an effective means of doing so. A review of the literature identified a study investigating the use of nebuliser breath actuation as a means of controlling nosocomial influenza infection (26). That study concluded that while the use of surgical masks by both staff and patients reduced the number of positive influenza tests, implementation of breath actuated nebulization therapy in combination with surgical masks resulted in a further protection of caregivers, using staff attendance records as the measure. In a separate bench study the same JN with both a breath actuated and the typical continuous mode and a VMN were characterised under paediatric breath settings (27). The results indicate that the breath actuated mode did indeed facilitate reduced emissions over the continuous mode for the JN, but interestingly, and consistent with previous observations, 
A

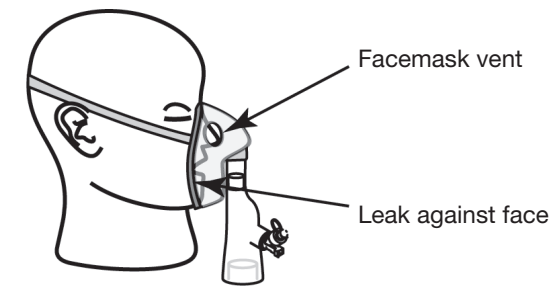

C

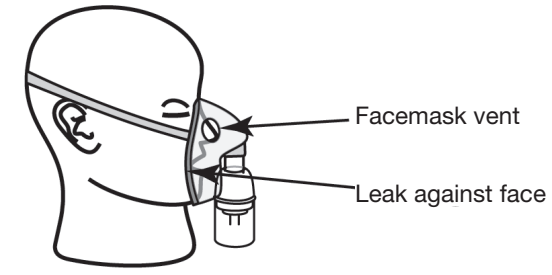

B

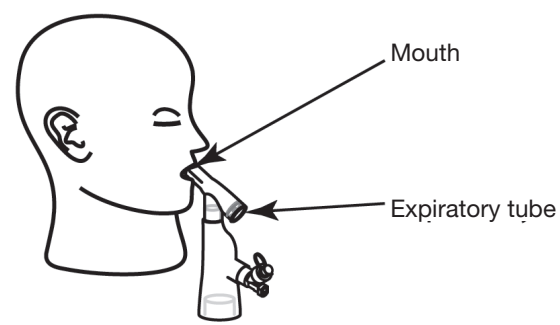

D

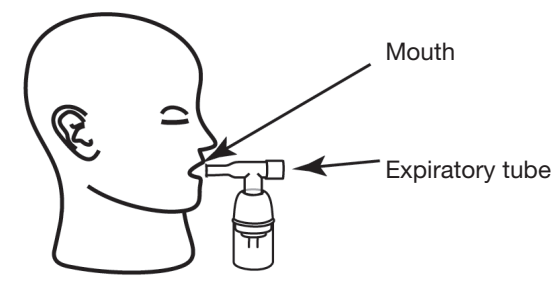

Figure 1 Nebuliser systems, their components and the features facilitating the potential for fugitive aerosol (A) VMN plus valved facemask (B) VMN plus mouthpiece (C) JN plus open facemask (D) JN plus mouthpiece. VMN, Vibrating Mesh Nebuliser. JN, Jet Nebuliser. [Adapted with permission (28)].

the VMN produced fewer fugitive emissions than $\mathrm{JN}$ in both the continuous mode and breath actuated mode. The reasons for this remain unclear, however, that study reported higher inhaled doses in the simulated patients for the VMN, and so with that fraction of aerosol no longer available for exhalation, limited the potential for fugitive aerosol. Additionally, there may be mis-timing of the breath actuation, whereby a fraction of the aerosol plume is generated late in the inspiratory phase, and so does not have the opportunity to deposit before it becomes entrained in the exhaled breath.

See Figure 1 for an illustration of each component of JN and VMN, and the potential points of fugitive aerosol exit to the environment.

\section{Non-invasive ventilation}

For those patients requiring increased, but not total ventilatory support, non-invasive mechanical ventilation (NIV) may be used. These systems include a mechanical ventilator, and single or dual limb (inhalation/exhalation) breathing circuits. Single limb circuits incorporate fixed leak valves to facilitate exhalation. The patient interface is usually a tight fitting, sealed FM, or an airtight ventilation hood.

A study characterised the dispersion distance of a JNgenerated aerosol when combined with NIV FM in a set up used to visualise to what extent exhaled particles could travel when a patient undergoes nebuliser therapy (29). It was found that for more severe lung injuries (reproduced using a breathing simulator), greater leakage through the vents of the NIV FM was seen. For a normal lung condition plus NIV FM, the maximum distance tracer particles could travel was 0.45 meters, for a mild lung injury 0.54 meters and for a severe lung injury, greater than 0.8 meters. These data further indicate the risk of emissions from JN.

Another study, by the same group, examined NIV and $\mathrm{JN}$-generated fugitive aerosols in conjunction with a hood and NIV FM (30). In this study, normal, mild and severe lung injury were examined with increasing inspiratory positive airway pressure (IPAP). The more severe the lung condition the smaller the dispersion distance of the exhaled aerosol. A maximum distance of 0.916 meters could be reached by the exhaled aerosol through the exhalation port when the NIV was used with the NIV FM and single limb circuit.

See Figure 2 for an illustration of each component of a non-invasive ventilation system, and the potential points of fugitive aerosol exit to the environment.

\section{High flow nasal therapy (HFNT)}

Some spontaneously breathing patients will be prescribed HFNT as a means of first line therapy and oxygenation management. HFNT is most often administered via nasal cannula or, in the case of weaning patients, via tracheostomy 
A

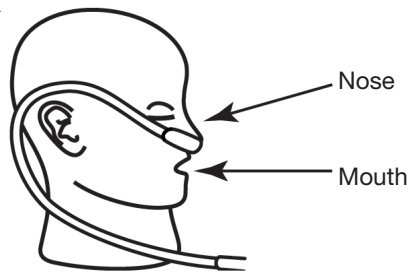

B

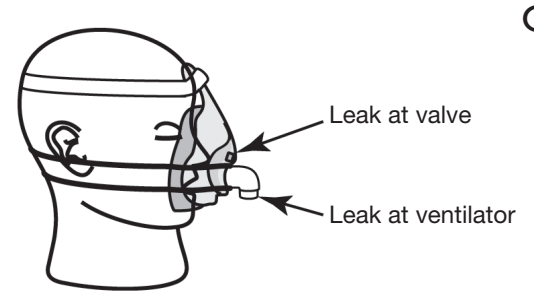

C

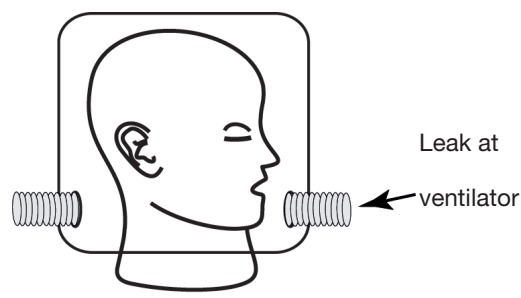

Figure 2 Non-invasive ventilation system and components, and the features facilitating the potential for fugitive aerosol. (A) High flow nasal cannula; (B) nonvasive facemask; (C) ventilation hood. [Adapted with permission (28)].

tube, and delivers air/oxygen mixes at rates that meet or exceed the patient's peak inspiratory flow rate. Increasingly common, HFNT is also used concurrently with aerosol therapy and prescribed gas flow rates can be as low as 2 to 8 litres per minute for infants, and 50 litres per minute for adults $(31,32)$.

Currently, there is only a single investigation of fugitive aerosol emissions during HFNT reported in the literature (33). In that, HFNT in combination with both nasal cannula and tracheostomy interfaces was assessed across adult and paediatric appropriate gas flow rates using VMN only. The results indicate that the quantity and characteristics of the fugitive aerosols were again influenced by the interface type, patient type and now, for the first time, the applied gas flow rate. There was a trend in the adult scenarios where, as the flow rate increased, the fugitive aerosol decreased. This was hypothesized to be a result of higher impactional aerosol losses within the nasal passages (with higher gas flows), and therefore there was less available to be blown out or exhaled by the patient. Further, for adults, the fugitive aerosols were comparable for both the nasal cannula and tracheostomy interfaces, however, there was a noticeable difference between those interfaces under paediatric conditions. Of note also, fugitive aerosol was recorded at both 0.8 and 2.2 meters from the patient model demonstrating the potential for distribution of aerosol throughout the local environment.

In a separate study investigating air dispersion during HFNT only (no aerosol), researchers examined air movements during HFNC versus continuous positive airway pressure (CPAP) (34). When flow rate was increased from 10 to $60 \mathrm{~L} / \mathrm{min}$, exhaled air dispersion increased from $65 \pm 15$ to $172 \pm 33 \mathrm{~mm}$ during HFNC. This may go towards explaining the trends noted in the HFNT plus VMN aerosol study above (33). With increasing lung severity, exhaled air distances from the manikin decreased. Air leakage of up to $620 \mathrm{~mm}$ occurred laterally during HFNC when the interface became loose. However, there are some limitations to the study. Smoke particles were used to track the potential dispersion of the exhaled aerosol. While this gives a good indication of how far the particles may travel, accuracy may be limited as the physicochemical properties of smoke particle likely differ from aerosol droplets. Nevertheless, this study again provides insight into the potential for contamination of the local environment.

\section{Patients in receipt of invasive ventilatory support}

Those patients with a significant or life-sustaining requirement for ventilatory support are prescribed invasive MV which involves instrumentation of the airways using a tracheostomy or endotracheal tube. Ventilation is facilitated by a mechanical ventilator that can provide the patient with volume-controlled or pressure-controlled support. The ventilator applies a positive pressure to the airways, and the breath is a combination of target tidal volume, breathing rate and inhalation to exhalation ratio. The choice of ventilation mode, and ventilation parameters will be institution and patient dependent. By their very design, ventilator circuits are intended to be fully-sealed systems that allow for accurate delivery of the prescribed tidal volume and or pressures, and as such, should be expected to allow for zero fugitive aerosols. Further, in an effort to safeguard the operation of the ventilator, exhalation cassettes or filters are generally interposed between the exhalation limb of the circuit and the ventilator itself. This prevents patient secretions, exhaled humidity and aerosol from entering and depositing in, or passing through the ventilator itself, to the external environment. However, it is noted that exhalation filters are often not employed due to reasons of cost.

Few studies have been conducted analysing fugitive 


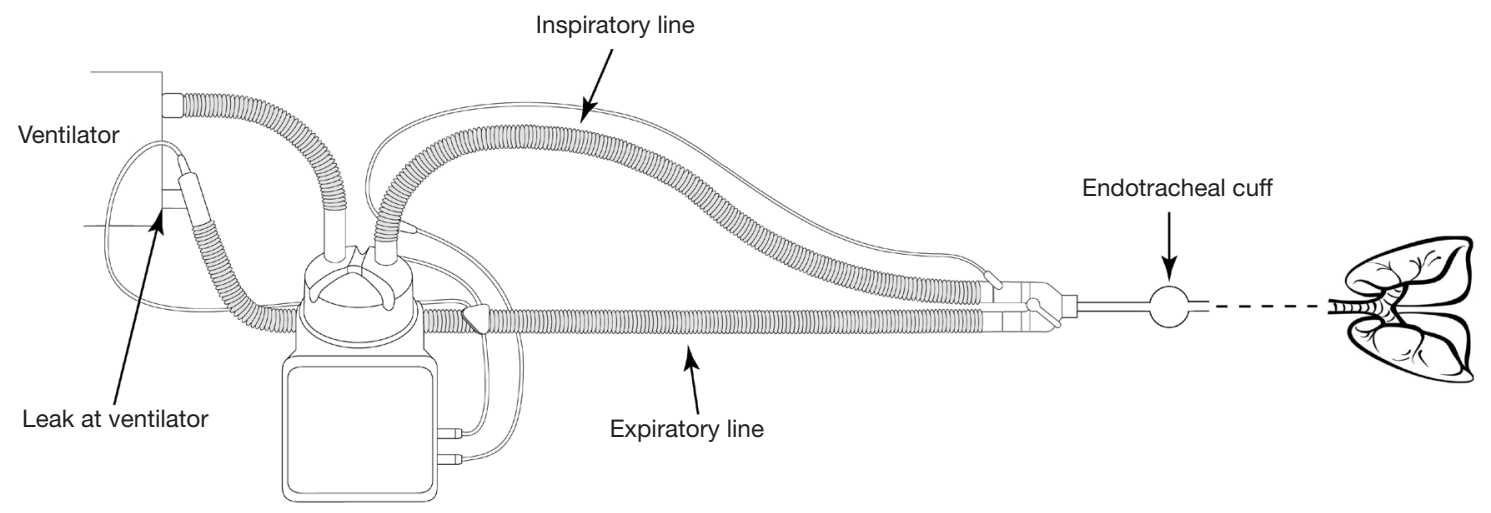

Figure 3 Invasive mechanical ventilation system and components, and the features facilitating the potential for fugitive aerosol.

emissions during invasive MV. Of those that were identified, the use of a filter and tidal volume were highlighted as contributing factors to fugitive aerosol emissions.

Filter use and the effect on fugitive aerosols during MV was first assessed by (35). That study investigated aerosol emitted from the expiratory port of a ventilator with and without proprietary filters. There, it was concluded that drug deposited at the expiratory port of the ventilator without filtering was 160 -fold higher than that deposited when using an expiratory filter. Proprietary filter usage was the most efficient outcome with $0.25 \%$ of the dose escaping through the filter, and out the expiratory port. These data underpin the benefit of using a protective filter on the exhaust port of a ventilator and how they can reduce fugitive emissions. In this study, it was also calculated that bystanders have a fugitive aerosol exposure risk of greater than $45 \%$ of the nominal dose in this set-up. This alone would be of concern considering the occupational exposure levels proposed above (1).

The effect of tidal volume on fugitive emissions during invasive $M V$ was assessed in a small study (36). There, unsurprisingly, higher tidal volumes were associated with increased fugitive aerosol emissions.

Figure 3 provides an illustration of each component of an invasive MV system, and the potential point of fugitive aerosol exit to the environment.

\section{Other factors}

Separate to nebuliser type, mode of nebuliser operation or ventilation mode, other potential influencers of exposure levels to fugitive aerosols emissions have been suggested. These include the type of therapeutic being aerosolised and the use of personal protective equipment (PPE).

\section{Therapeutic type}

As detailed above, the range of therapeutics regularly aerosolised is broad. It is known that factors such as the physicochemical characteristics of formulations can affect droplet size, but the effect on emissions is less well characterised. A 2019 study did examine potential exposure of home healthcare workers to aerosolized medication (37). Five drugs were tested including; ipratropium bromide, budesonide, albuterol sulfate, sodium chloride and deionised water at three distances under $0.55 \mathrm{~m}$. Deionised water droplets had a smaller particle size distribution compared to all of the other four drug solutions. However, total aerosol mass concentration in the breathing zone ranged from $2.29-10.2 \mu \mathrm{g} \cdot \mathrm{m}^{-3}$ but was not significantly affected by therapeutic type, and would suggest that therapeutic type or formulation does not influence emissions.

\section{PPE}

PPE is sometimes reportedly used by bystanders when delivering treatment to patients. Discussed above, they may be used by the patient or bystander, or both (26). One study looked at a small sample of bystanders and analysed aerosol concentrations inside and outside their masks (N95 and a standard surgical mask were tested) when they administered drug to a patient (38). The total concentration inside the N95 ranged from $5-7,224 \mathrm{~cm}^{-3}$ while the surgical mask ranged from $108-13,035 \mathrm{~cm}^{-3}$. It was found that the N95 offered better protection against aerosol particles than the surgical mask. A separate study examined inhalation exposure of bystanders when varying air exchange rates, distances and breathing rates in combinations of no PPE and PPE (a surgical mask and N95 respectively). Results 
from this study suggest that for an unprotected bystander, ventilation was the most effective measure of reducing exposure to fugitive emissions. For a protected bystander, the N95 respirator with a proper seal was 20 times more efficient than a surgical mask (39).

\section{Conclusions \& future work}

Current knowledge of fugitive emissions present in the ICU is very limited. Further studies, in vitro and in vivo, need to be conducted to analyse to what extent are fugitive emissions present in the ICU and what quantity could potentially be inhaled by bystanders.

Future work that needs to be conducted includes analysing the emissions from a variety of breath-actuated nebulisers and examining whether they completely or partially reduce emissions. Analysing aerosol mass concentrations during HFNT for adults and paediatrics with varying breathing profiles is also recommended. Tidal volume and ventilation mode should be addressed during non-invasive positive pressure ventilation and invasive ventilation for fugitive emissions.

Eventually, laboratory experiments need to be expanded to investigate real scenarios to examine fugitive emissions in a range of environments (homecare settings, clinical environments, etc.), where variations in behaviour and ventilation are likely to occur. These studies should include examining the differences between common-usage procedures and best-practice.

Finally, on the basis of the findings detailed above, the risk of fugitive aerosols in the ICU may be mitigated through the use of combinations of the following, as appropriate; vibrating mesh type nebulizers that generate passive, low velocity aerosols, lower oxygen gas flow rates, smaller tidal volumes and the inclusion of filters on both handheld nebulisers and mechanical ventilators.

\section{Acknowledgments}

Funding: This work represents research funded by the Irish Research Council under the Government of Ireland Postgraduate Scholarship Programme-GOIPG/2018/1968.

\section{Footnote}

Reporting Checklist: The authors have completed the Narrative Review reporting checklist. Available at http:// dx.doi.org/10.21037/atm-20-2280
Provenance and Peer Review: This article was commissioned by the Guest Editors (Dr. James B. Fink and Dr. Zhe Luo) for the series "Medical Aerosol in Acute and Critical Care" published in Annals of Translational Medicine. The article was sent for external peer review organized by the Guest Editors and the editorial office.

Conflicts of Interest: The authors have completed the ICMJE uniform disclosure form (available at http://dx.doi. org/10.21037/atm-20-2280). The series "Medical Aerosol in Acute and Critical Care" was commissioned by the editorial office without any funding or sponsorship. CO, JAM, and $\mathrm{MAB}$ reports grants from Irish Research Council, during the conduct of the study. MJ, AO, and RM reports personal fees from Aerogen Limited, outside the submitted work. The authors have no other conflicts of interest to declare.

Ethical Statement: The authors are accountable for all aspects of the work in ensuring that questions related to the accuracy or integrity of any part of the work are appropriately investigated and resolved.

Open Access Statement: This is an Open Access article distributed in accordance with the Creative Commons Attribution-NonCommercial-NoDerivs 4.0 International License (CC BY-NC-ND 4.0), which permits the noncommercial replication and distribution of the article with the strict proviso that no changes or edits are made and the original work is properly cited (including links to both the formal publication through the relevant DOI and the license). See: https://creativecommons.org/licenses/by-nc-nd/4.0/.

\section{References}

1. Frank E, Ishau S, Maier A, et al. An occupational exposure limit (OEL) approach to protect home healthcare workers exposed to common nebulized drugs. Regul Toxicol Pharmacol 2019;106:251-61.

2. Beach JR, Campbell M, Andrews DJ. Exposure of health care workers to pentamidine isethionate. Occup Med (Lond) 1999;49:243-5.

3. Dimich-Ward H, Wymer ML, Chan-Yeung M. Respiratory Health Survey of Respiratory Therapists. Chest 2004;126:1048-53.

4. Mapp CE, Boschetto P, Maestrelli P, et al. Occupational Asthma. Am J Respir Crit Care Med 2005;172:280-305.

5. Kern DG, Frumkin H. ASTHMA IN RESPIRATORY THERAPISTS. Annals of Internal Medicine 
1989;110:767-73.

6. Carnathan B, Martin B, Colice G. Second hand (S)albuterol: RT exposure risk following racemic albuterol. Respir Care 2001;46:1084.

7. Chughtai AA, Seale H, MacIntyre CR. Availability, consistency and evidence-base of policies and guidelines on the use of mask and respirator to protect hospital health care workers: a global analysis. BMC Res Notes 2013;6:216.

8. Diaz-Ortega JL, Bennett JV, Castaneda D, et al. Aerosolized MMR vaccine: Evaluating potential transmission of components to vaccine administrators and contacts of vaccinees. Biologicals 2012;40:278-81.

9. Daniels LM, Juliano J, Marx A, et al. Inhaled Antibiotics for Hospital-Acquired and Ventilator-Associated Pneumonia. Clin Infect Dis 2017;64:386-7.

10. WHO. Implementation of the Global Action on Antimicrobial Resistance. 2018.

11. Linn WS, Gong H Jr, Anderson KR, et al. Exposures of health-care workers to ribavirin aerosol: a pharmacokinetic study. Arch Environ Health 1995;50:445-51.

12. Balmes JR, Estacio PL, Quinlan P, et al. Respiratory effects of occupational exposure to aerosolized pentamidine. J Occup Environ Med 1995;37:145-50.

13. Sessink PJM, Nyulasi T, Haraldsson ELM, et al. Reduction of Contamination with Antibiotics on Surfaces and in Environmental Air in Three European Hospitals Following Implementation of a Closed-System Drug Transfer Device. Ann Work Expo Health 2019;63:459-67.

14. Ehrmann S, Roche-Campo F, Bodet-Contentin L, et al. Aerosol therapy in intensive and intermediate care units: prospective observation of 2808 critically ill patients. Intensive Care Med 2016;42:192-201.

15. Le Brun PPH, de Boer AH, Frijlink HW, et al. A review of the technical aspects of drug nebulization. Pharm World Sci 2000;22:75-81.

16. Waldrep JC, Dhand R. Advanced nebulizer designs employing vibrating mesh/aperture plate technologies for aerosol generation. Curr Drug Deliv 2008;5:114-9.

17. Adorni G, Seifert G, Buttini F, et al. Aerosolization Performance of Jet Nebulizers and Biopharmaceutical Aspects. Pharmaceutics 2019;11:10.

18. Forde E, Kelly G, Sweeney L, et al. Vibrating Mesh Nebulisation of Pro-Antimicrobial Peptides for Use in Cystic Fibrosis. Pharmaceutics 2019;11:11.

19. Chemaly RF, Shah DP, Boeckh MJ. Management of respiratory viral infections in hematopoietic cell transplant recipients and patients with hematologic malignancies.
Clin Infect Dis 2014;59 Suppl 5:S344-51.

20. Montgomery VL, Eid NS. Low-dose beta-agonist continuous nebulization therapy for status asthmaticus in children. J Asthma 1994;31:201-7.

21. Collins N. Nebulizer therapy in cystic fibrosis: an overview. J R Soc Med 2009;102 Suppl 1:11-7.

22. Wittgen BP, Kunst PW, Perkins WR, et al. Assessing a system to capture stray aerosol during inhalation of nebulized liposomal cisplatin. J Aerosol Med 2006;19:385-91.

23. Englund JA, Piedra PA, Ahn YM, et al. High-dose, shortduration ribavirin aerosol therapy compared with standard ribavirin therapy in children with suspected respiratory syncytial virus infection. J Pediatr 1994;125:635-41.

24. Matlock D, Buchan RM, Tillery M. A local exhaust ventilation system to reduce airborne ribavirin concentrations. Am Ind Hyg Assoc J 1991;52:428-32.

25. McGrath JA, O'Sullivan A, Bennett G, et al. Investigation of the Quantity of Exhaled Aerosols Released into the Environment during Nebulisation. Pharmaceutics 2019;11:75.

26. Copelin D. Implementation of a Breath-Actuated Nebulizer Regimen May Reduce Nosocomial Influenza Acquired by Exposure to Fugitive Droplet Emissions From Continuous Nebulizers Whose Droplets Produced During Exhalation Are Vented to the Environment. Respiratory Care 2018;63:3016143.

27. O'Toole C, McGrath J, Bennett G, et al. Fugitive Emissions from a Breath Actuated Jet Nebuliser and a Vibrating Mesh Nebuliser for a Paediatric Patient. ISES-ISIAQ 2019; Kaunas, Lithuania. doi: 10.13140/ RG.2.2.10795.59686

28. Bennett G, Joyce M, Fernández EF, et al. Comparison of aerosol delivery across combinations of drug delivery interfaces with and without concurrent high-flow nasal therapy. Intensive Care Med Exp 2019;7:20.

29. Hui DS, Chow BK, Chu LCY, et al. Exhaled Air and Aerosolized Droplet Dispersion During Application of a Jet Nebulizer. Chest 2009;135:648-54.

30. Hui DS, Chow BK, Lo T, et al. Exhaled Air Dispersion During Noninvasive Ventilation via Helmets and a Total Facemask. Chest 2015;147:1336-43.

31. Réminiac F, Vecellio L, Loughlin RM, et al. Nasal high flow nebulization in infants and toddlers: An in vitro and in vivo scintigraphic study. Pediatr Pulmonol 2017;52:337-44.

32. Frat JP, Thille AW, Mercat A, et al. High-Flow Oxygen through Nasal Cannula in Acute Hypoxemic Respiratory 
Failure. N Engl J Med 2015;372:2185-96.

33. McGrath JA, O'Toole C, Bennett G, et al. Investigation of Fugitive Aerosols Released into the Environment during High-Flow Therapy. Pharmaceutics 2019;11:254.

34. Hui DS, Chow BK, Lo T, et al. Exhaled air dispersion during high-flow nasal cannula therapy versus CPAP via different masks. Eur Respir J 2019;53:1802339.

35. Ari A. Secondhand aerosol exposure during mechanical ventilation with and without expiratory filters: an in-vitro study. Indian J Respir Care 2016;5:1-6.

36. Bennett G, Joyce C, Joyce M, et al. Effect of tidal volume on fugitive emissions during mechanical ventilation. Eur Respir J 2018;52.

Cite this article as: O'Toole C, Joyce M, McGrath JA, O'Sullivan A, Byrne MA, MacLoughlin R. Fugitive aerosols in the intensive care unit: a narrative review. Ann Transl Med 2021;9(7):592. doi: 10.21037/atm-20-2280
37. Elmashae Y, Yermakov M, Frank E, et al. Exposure of home-attending healthcare workers to aerosolized medications (simulation study). J Aerosol Sci 2019;133:49-55.

38. Elmashae RBY, Grinshpun SA, Reponen T, et al. Performance of two respiratory protective devices used by home-attending health care workers (a pilot study). J Occup Environ Hyg 2017;14:D145-9.

39. Ollier K, Leppänen M, Wu B, et al. Inhalation Exposure and Respiratory Protection of Home Healthcare Workers Administering Aerosolized Medications (Simulation Study). Aerosol Air Qual Res 2019;19:937-44. 